\section{La naturaleza como material de construcción}

\author{
Jesús Vassallo \\ Editor invitado
}

Creo sinceramente que no es una exageración el decir que la actual crisis medioambiental, provocada por el hombre, es un evento histórico de una magnitud tal que reclama una reconsideración completa y profunda de la actividad humana en el planeta. En ese sentido, y para los arquitectos, supone un desarrollo comparable a la invención de la agricultura o la revolución industrial, ya que conllevará, lo queramos o no, una transformación radical de nuestra forma de construir.

Los problemas y desafíos a los que nos enfrentamos hoy no son sin embargo totalmente nuevos. De hecho, históricamente cada crisis medioambiental se ve seguida de un aumento del nivel de conciencia y conocimiento especializado. Dicha generación de conocimiento ha sido notable en las últimas décadas tanto en las ciencias como en las humanidades medioambientales, un trabajo al que los arquitectos, si bien con honrosas excepciones, han sido tan solo contribuyentes ocasionales.

La posición marginal de los arquitectos en estas discusiones es sorprendente, no solo por la responsabilidad que conlleva el porcentaje de emisiones y consumo energético materializado en el entorno construido, sino porque la arquitectura, habiéndose definido tradicionalmente como el contrario de la naturaleza, ha desarrollado a lo largo de los siglos un cuerpo de conocimiento general de una gran riqueza y profundidad acerca de ésta.

Si bien mucha de la literatura medioambiental contemporánea descarta las ideas de naturaleza implícitas en gran parte de la historia y teoría de la arquitectura como románticas u obsoletas, creo sin embargo, y esa es mi premisa como editor de este número, que éste es un buen momento para hacer acopio de dicha tradición y evaluar sus posibles contribuciones al cambio de paradigma actual. En ultima instancia, el desafío al que nos enfrentamos es la necesaria disolución de la dicotomía tradicional entre los conceptos de cultura y naturaleza.

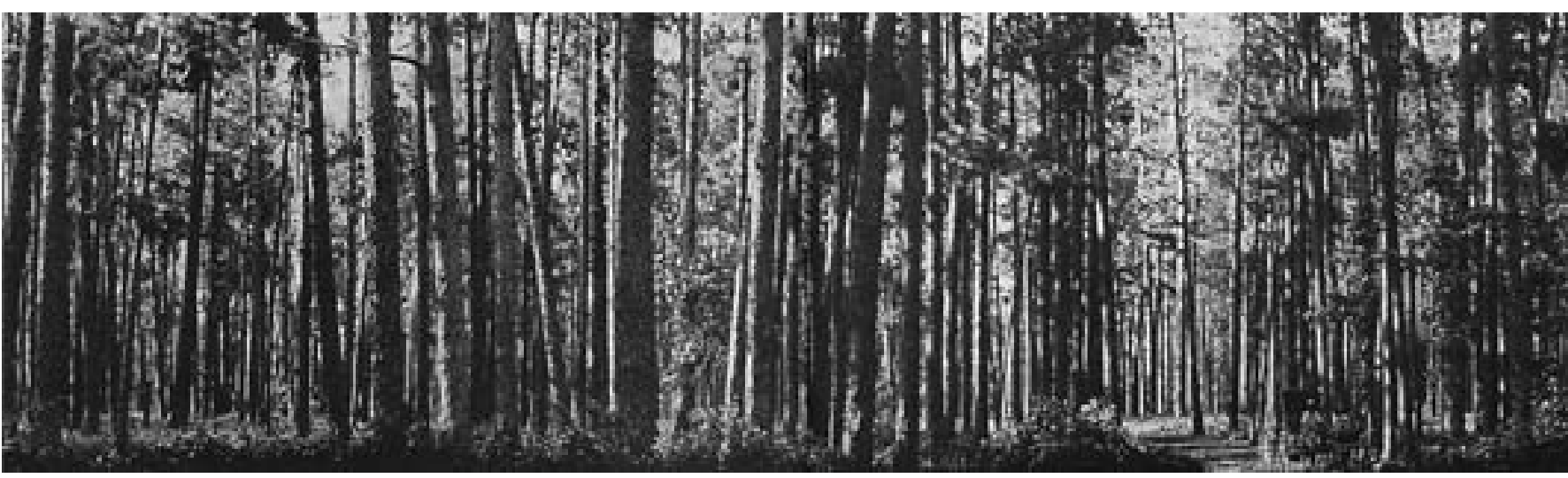


En ese contexto, la arquitectura, que se ha imaginado a sí misma como cultura cristalizada, tiene tanto un punto de vista privilegiado como una gran responsabilidad. La idea es simple pero radical: necesitamos redefinir la actividad humana en general -la economía es el mejor ejemplo-, y sus productos -lo construido-, como fenómenos internos de la naturaleza. Aunque esta propuesta puede parecer poco intuitiva, hay sin embargo múltiples ejemplos y precedentes históricos que podemos utilizar, si pretendemos reconstruir nuestras definiciones de lo natural y lo arquitectónico y producir un nuevo paradigma capaz de impulsarnos en el próximo siglo.

Desde que el poder de la industrialización fue revelado, los arquitectos se han esforzado, cíclica y gradualmente, por repensar la relación de la disciplina de la arquitectura con la naturaleza. Este fue el tema principal en el movimiento Arts and Crafts, con su búsqueda de nuevas formas en lo natural, e incluso de forma más explícita en la Ciudad Jardín, que imaginó la naturaleza como el principal material de construcción a la escala de la ciudad. También dentro del movimiento moderno, una vez cedieron las primeras fiebres, emergieron ejemplos de esta tendencia: tal vez la Broadacre City de Frank Lloyd Wright sea el más destacado. Los arquitectos nórdicos de la segunda generación de la modernidad también incorporaron la naturaleza de forma integral en su manera de entender la arquitectura, como atestiguan los experimentos que realizaron Arne Jacobsen y Alvar Aalto en sus propias casas, y con sus propias manos. Más cerca de nuestros días, los intentos de Herzog \& de Meuron de construir literalmente con algas o musgo han complicado la distinción entre naturaleza y artificio, prefigurando nuestro interés contemporáneo por los materiales de construcción naturales. Mientras la construcción en masa con madera transita hacia el éxito comercial y los experimentos con tierra, adobe o bambú se vuelven más comunes, emerge un camino según el cual la arquitectura algún día crecerá, al menos conceptualmente, de la tierra, en lugar de imponerse sobre ella. La promesa de este camino alberga también el potencial de ayudarnos a desdibujar la dicotomía con la que enfrentamos los entornos rurales y urbanos, incluso la posibilidad de imaginar y diseñar nuestros ciclos de producción y consumo como parte de un gradiente más amplio de ciclos agrarios y naturales. Con ese fin, este número recoge una serie de ensayos y ejemplos especíicos, de temática tanto histórica como contemporánea y diseminados en un amplio abanico de escalas, con el fin de contribuir a repensar la naturaleza como material de construcción o, alternativamente, la arquitectura como vehículo de la naturaleza. Puede que haya llegado la hora de dejar entrar al bosque en nuestras ciudades.
Vista panorámica en la propiedad de bosque de pino amarillo de la Thompson \& Tucker Lumber Company vista desde la parte oriental de George Smith Survey, catorce millas al sur de Willard, Texas, 1908.

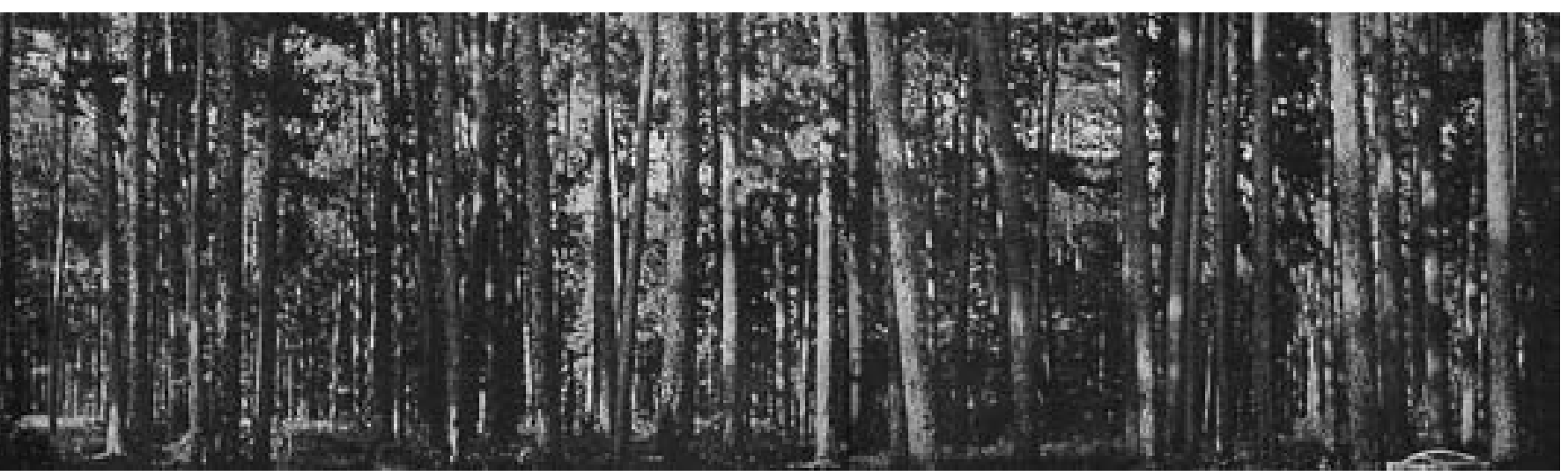

